\title{
MORBIDITY, MORTALITY, HEALTH EXPENDITURES AND ANNUITIZATION
}

\author{
KAM KI TANG \\ JIE ZHANG
}

\author{
CESIFO WORKING PAPER NO. 2086 \\ CATEGORY 10: EMPIRICAL AND THEORETICAL METHODS \\ August 2007 \\ Presented at CESifo Venice Summer InStitute, July 2007 \\ WORKSHOP ON "LONGEVITY AND ANNUITIZATION”
}
An electronic version of the paper may be downloaded
- from the SSRN website: Www.SSRN.com
- from the RePEc website: $\quad$ www.RePEc.org
- from the CESifo website: $\quad$ www.CESifo-group.org/wp




\title{
MORBIDITY, MORTALITY, HEALTH EXPENDITURES AND ANNUITIZATION
}

\begin{abstract}
In this paper we explore the implication of a morbidity risk for the relationship between longevity and annuitization. We divide old-age life into two periods with uncertain survival from the end of the first to the end of the second. We show that a rise in the survival rate causes different patterns of change in annuitization, depending on the initial survival rate. When the initial survival rate is low (high), there is full (partial) annuitization. There is thus an inverse relationship between longevity and annuitization.
\end{abstract}

JEL Code: E2, J1, L1.

Keywords: annuity, morbidity, mortality, precautionary saving.

Kam Ki Tang

School of Economics

University of Queensland

Brisbane, Qld 4072

Australia

kk.tang@uq.edu.au
Jie Zhang

School of Economics

University of Queensland

Brisbane, Qld 4072

Australia

j.zhang@uq.edu.au

12 August 2007 


\section{Introduction}

In many countries voluntary annuity markets remain thin and the annuitized portion of savings may have been falling despite steady population aging. ${ }^{1}$ In this paper we explore the implication of a morbidity risk in old age for the relationship between longevity and annuitization. We divide old-age life into two periods with uncertain survival from the end of the first to the end of the second. We show that a rise in the survival rate causes different patterns of change in annuitization, depending on the initial survival rate. When the initial survival rate is low, there is full annuitization and a rise in the survival rate tends to raise the amount of annuities. When the initial survival rate is high enough, non-annuitized saving becomes positive and accordingly there is partial annuitization; a further rise in the survival rate may reduce the degree of annuitization. We also consider an extension with the dependence of longevity on morbidity.

The negative relationship between a rising survival rate in the second period of old age and the annuitized fraction of savings is caused by the morbidity risk that involves a lumpy cost of healthcare in the event of falling sick for a long period of time. Across most countries, on average an elderly person spends much more on healthcare than a younger person. For the elderly, health spending is important in moderating the morbidity problems that come naturally with ageing. Increasing longevity in most OECD countries means that health expenditure is likely to climb relative to income in the future.

Health expenditure in the old age can be financed by out-of-pocket payment from retirement savings or by health insurance purchased at earlier ages. With a perfect health insurance market, there would be no need to have out-of-pocket

\footnotetext{
${ }^{1}$ The coexistence of rising longevity and falling annuitization has become a theme of the 2007 Workshop at Venice Summer Institute, held in July 2007 in Venice, Italy. The relatively thin market of voluntary annuities has been noted in the literature, e.g. Piggott, Valdez and Detzel (2005).
} 
payment. However, due to the well-known problems of moral hazard and adverse selection, the health insurance market is typically incomplete with partial or limited coverage. ${ }^{2}$ For instance, in the Unites States, it was estimated that over 60 percent of those aged 65+ will need some long-term care (LTC) in their remaining lifetime while the Medicare covers only 100 days of long-term cares in certain limited circumstance. About 30 percent of the elderly are believed to be excluded from the LTC insurance market all together because of their poor health. On the one hand, publicly provided LTC services in the United States, mainly via the Medicaid, are narrowly targeting the poorest with income and asset tested qualifications. On the other hand, no more than 5 to 7 percent of the elderly have taken up private policy (see Murtaugh, Spillman and Warshawsky, 2001). The need for out-of-pocket health expenditure at the old age to cope with the risk of long term illness forces people to arrange precautionary savings and thus people may not fully annuitize their retirement savings.

Our work relates to some existing studies. In a seminal paper of Yarri (1965), under the assumptions of a time separable utility function, actuarially fair annuities and the absence of bequest motives, it is optimal for a retiree to fully annuitize his or her wealth. The intuition is that annuities dominate conventional forms of assets in terms of the rate of return. In their recent extension of Yarri's model, Davidoff, Brown and Diamond (2005) show that when markets are complete, full annuitization can still remain optimal without intertemporal separability or the expected utility axioms and even without actuarial fairness of annuities. In reality, however, few retirees choose to annuitize their savings aside from mandatory annuities such as Social Security and employer-provided pensions.

\footnotetext{
${ }^{2}$ According to Nardi, French and Jones (2006), the average out-of-pocket medical expenditure rises rapidly with age; for example, the average medical expenditure for a woman in bad health rises from $\$ 1,200$ at age 70 to $\$ 19,000$ at age 100 .
} 
A number of explanations have been put forward in the literature to explain this annuity puzzle: moral hazard, adverse selection, uncertainties in health and medical expenses, and bequest motives. The moral hazard problem arises when annuities induce incentives to invest in health for improvement in longevity, as captured in Philipson and Becker (1998). The adverse selection problem arises as people with better (poorer) health than the average of their cohort will have a stronger (less) incentive to purchase annuity, driving down the actual returns of annuity. This may cause substantial costs for annuities and may thus invalidate the dominance of annuities over other forms of assets in the rate of return, as argued by Friedman and Warshawsky (1990) and Brugiavini (1993). ${ }^{3}$ Nevertheless, empirical evidence indicates that even though adverse selection will lead to annuity returns being lower than the actuarially fair rates, annuity pricing in reality still should not revoke the theoretical prediction of complete annuitization of retirement savings (Turra and Mitchell, 2004). A corollary of this result is that, even if there is compulsory annuitization of wealth via Society Security, as long as the annuitization is not complete, individuals should still have the incentive to purchase additional annuity products in the markets. Therefore, adverse selection and over-annuitization via Society Security do not seem to provide sufficient explanations for the thin voluntary annuity market.

The role of uncertainties in health status and medical expenses has recently been examined as an explanation of low annuitization rates of wealth. Turra and Mitchell (2004) present evidence that uncertain out-of-pocket medical expenses make annuities less attractive by using dynamic discrete choice estimation and household data in the US. Though our paper shares a similar feature with Turra and Mitchell

\footnotetext{
${ }^{3}$ Also, see Doyle, Mitchell and Piggott (2004) for the cost figures of adverse selection in Australia.
} 
(2004) by taking into account uncertain health status and uninsurable medical expenses, we use an analytical approach in dealing with annuitization and focus on comparative static analysis.

In the broader literature of life cycle models, Hubbard, Skinner, and Zeldes (1995), Palumbo (1999), and De Nardi, French, and Jones (2006) have also investigated how the uncertainty in medical expenses can help explain why the elderly run down their assets much more slowly than predicted by standard life-cycle models. Thus, their studies focus on the overall size of savings rather than the degree of annuitizing savings, while our paper (and Turra and Mitchell 2004 as well) focus on both.

In this paper, we analyze how longevity can affect the annuitized portion of wealth differently in the presence of an uncertainty in health status and medical expenses. An interesting finding in this paper is that rising longevity or falling mortality may reduce the annuitized portion of wealth. In coping with uncertain health status and lumpy out-of-pocket medical expenses, it is rational that individuals entering retirement hold sufficient non-annuitized savings for precaution. The implication of doing so is that, when mortality falls or longevity rises, the level of annuitization may actually decline, leading to a possible negative relationship between longevity and annuitization. This challenges the conventional perception of a positive relationship between longevity and annuitization.

The rest of the paper proceeds as follows. Section 2 introduces the model and derives its implications for the relationship between longevity and annuitization facing a morbidity risk and a lumpy health cost. Section 3 provides a numerical example. Section 4 extends the simple model to consider the dependence of mortality on morbidity. The last section concludes. 


\section{The model}

Throughout the paper we assume a unit mass of identical mature adults entering their old age (e.g. 60). Each of them has an accumulated wealth of $W$ at the beginning of time $t_{0}$. We divide the planning horizon into two periods as indicated below:

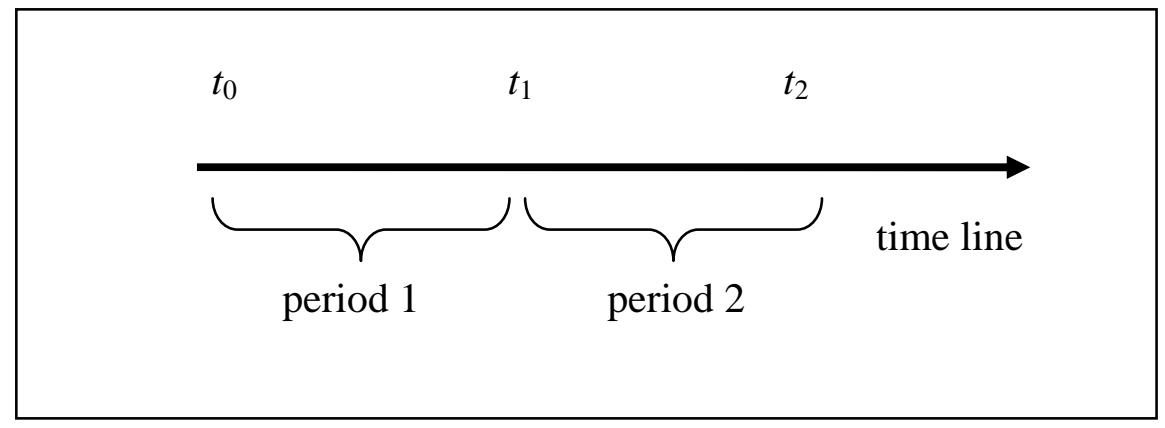

There is certain survival but uncertain health status in the first period, while there is uncertain survival through the second period at $t_{1}$. Lifetime ends at the end of period 2, at $t_{2}$. The sequence of events is described as follows.

\section{Sequence of events}

At the beginning of period 1, i.e. at time $t_{0}$, agents make decisions on savings and on the fraction of savings to annuitize. Each unit of an annuity purchased at the beginning of period 1 will pay out an amount $\alpha$ in the second period conditional on survival. So it is a deferred rather than immediate annuity, with period 1 being the investing phase and period 2 being the income phase. ${ }^{4}$ The agent decides on the amount of annuity $A \geq 0$ that he or she would like to purchase. The non-annuitized savings $S$ made at the beginning of period 1 will earn an interest income $r S$ or can be terminated to pay for the medical expenses.

\footnotetext{
${ }^{4}$ In the U.S. deferred annuity has a tax advantage over traditional saving account because the interest earned on a deferred annuity is tax-deferred till withdrawn. We abstract from this tax advantage.
} 
After the decision on annuitized and non-annuitized savings is made, the health status of each agent in period 1 begins to reveal. There are two types of health status in period 1: sick or healthy with certain survival through period 1 . The probability of morbidity is equal to $\pi$ and accordingly the probability of being healthy is equal to $1-\pi$. If sick in period 1 , an agent will need health care that requires a medical expense. The cost of healthcare is equal to $\theta M, 1>\theta>0$. Here $\theta$ can be considered a policy parameter in the form of subsidies on medical expenses. We abstract from health insurance and regard this medical cost as exogenous and paid out-of-pocket by each agent. ${ }^{5}$

At time $t_{1}$, the health status of agents in period 2 is revealed. There are two types of health status for this age group: death at $t_{1}$ or survival to $t_{2}$. The probability of death for agents at age $t_{1}$ is equal to $q$; the probability of their survival to $t_{2}$ is thus equal to1- $q$. We assume that $q$ is exogenous.

The scenario described above is simple. Nevertheless, it captures the trade-off between the morbidity risk and the longevity risk as they compete for a given amount of resource for each agent. We will consider an extension later in this paper.

The annuity market is assumed to be actuarially fair; that is, annuity provision makes zero profits. With actuarially fair annuities, we have the following condition per unit of annuity purchase: $\alpha(1-q)=1+r$ where $r$ is the market interest rate. For the purpose of this paper, we treat the interest rate as exogenous. Thus, the rate of return on per unit annuity purchase is equal to

$$
\alpha=\frac{1+r}{1-q}
$$

\footnotetext{
${ }^{5}$ Given the incompleteness of the insurance market for morbidity risks, agents have to pay part of the health cost through out-of-pocket resources. In this sense, abstraction from health insurance simplifies the analysis.
} 


\section{Objective function}

The expected utility of the agent at the beginning of period 1 is

$$
E_{t_{0}}(U(\cdot)) \equiv(1-\pi)\left[U\left(C_{1}^{h}\right)+(1-q) U\left(C_{2}^{h}\right)\right]+\pi\left[U\left(C_{1}^{s}\right)+(1-q) U\left(C_{2}^{s}\right)\right]
$$

where $C_{j}^{i}$ is consumption in period $j(j=1,2)$ with health status $i$ (s for being sick and $h$ for being healthy in period 1). $E_{t_{0}}$ is the expectation operator with information available at $t_{0}$. For notational simplicity, we ignore discounting. The utility function is increasing and concave: $U^{\prime}(\cdot)>0, U^{\prime \prime}(\cdot)<0$. Further, we adopt Inada conditions: $U^{\prime}\left(C_{j}^{i}\right) \rightarrow 0$ if $C_{j}^{i} \rightarrow \infty$ and $U^{\prime}\left(C_{j}^{i}\right) \rightarrow \infty$ if $C_{j}^{i} \rightarrow 0$

\section{Budget constraints}

If the health status in period 1 turns out to be poor, the budget constraints for periods 1 and 2, respectively, are

$$
\begin{gathered}
C_{1}^{s}+\theta M+A+S^{s}=W \\
C_{2}^{s}=\alpha A+(1+r) S^{s}
\end{gathered}
$$

where $W$ is initial wealth, $A$ is annuity savings, and $S$ is non-annuitized regular savings. The difference between annuities and regular savings is not only that the former have a higher rate of return as seen in (1), but also that the latter can be terminated by simply forging the interest income. The termination becomes necessary when one falls sick and needs to pay for the medical expense $\theta M$. We assume that old-aged agents are unable to borrow and thus cannot possess negative amounts of annuitized and non-annuitized assets, i.e. $A \geq 0$ and $S^{s} \geq 0$ as in many related studies 
(e.g., Hubbard et al., 1995; Turra and Mitchell, 2004). ${ }^{6}$ This immediately implies that any healthcare expenditure has to be made out-of-pocket.

If the health status in period 1 turns out to be good, the budget constraints for periods 1 and 2, respectively, are

$$
\begin{gathered}
C_{1}^{h}+A+S^{h}=W \\
C_{2}^{h}=\alpha A+(1+r) S^{h}
\end{gathered}
$$

The budget difference between the good and poor health statuses is caused by the outof-pocket payment of the healthcare expense. Note that under $U^{\prime}(C)>0$ the budget constraints must hold in strict equality in any optimal solution in this model.

The problem of the agent at the beginning of period 1 becomes

$$
\begin{aligned}
\max _{A, S^{h}, S^{s}} E_{t_{0}}(U(\cdot)) \equiv & \max _{A, S^{h}, S^{s}}(1-\pi)\left[U\left(C_{1}^{h}\right)+(1-q) U\left(C_{2}^{h}\right)\right] \\
& +\pi\left[U\left(C_{1}^{s}\right)+(1-q) U\left(C_{2}^{s}\right)\right]
\end{aligned}
$$

subject to the budget constraints (3)-(6). The Kuhn-Tucker optimal conditions are:

$$
\begin{gathered}
\frac{\partial E_{t_{0}}(U(\cdot))}{\partial S^{s}}=\pi\left[-U^{\prime}\left(C_{1}^{s}\right)+(1-q)(1+r) U^{\prime}\left(C_{2}^{s}\right)\right] \leq 0, \quad S^{s} \geq 0, \\
\frac{\partial E_{t_{0}}(U(\cdot))}{\partial S^{s}} S^{s}=0 ; \\
\frac{\partial E_{t_{0}}(U(\cdot))}{\partial S^{h}}=(1-\pi)\left[-U^{\prime}\left(C_{1}^{h}\right)+(1-q)(1+r) U^{\prime}\left(C_{2}^{h}\right)\right] \leq 0, \quad S^{h} \geq 0, \\
\frac{\partial E_{t_{0}}(U(\cdot))}{\partial S^{h}} S^{h}=0 ; \\
\frac{\partial E_{t_{0}}(U(\cdot))}{\partial A}=(1-\pi)\left[-U^{\prime}\left(C_{1}^{h}\right)+\alpha(1-q) U^{\prime}\left(C_{2}^{h}\right)\right]+ \\
\pi\left[-U^{\prime}\left(C_{1}^{s}\right)+\alpha(1-q) U^{\prime}\left(C_{2}^{s}\right)\right] \leq 0, \quad A \geq 0, \quad \frac{\partial E_{t_{0}}(U(\cdot))}{\partial A} A=0 .
\end{gathered}
$$

\footnotetext{
${ }^{6}$ However, it is interesting to study in future research a financial product that allows agents to borrow against their annuity assets, facing the possibility that some of them will die before receiving their annuity income, as suggested by Eytan Sheshinski at the Venice Workshop.
} 
These above conditions, the budget constraints and the actuarial-fairness condition of annuities determine implicitly the relationships among the optimal amounts of annuities, non-annuitized savings and consumption. While the annuity variable $A$ is the same across different health statuses over morbidity, the converse is true for nonannuitized savings and consumption. We use these conditions and constraints to establish the result below, and relegate the proofs of all propositions to the Appendix.

Proposition 1. The amount of non-annuitized savings is equal to zero with poor health and is positive or zero with good health: $S^{h} \geq S^{s}=0$. Also, the amount of annuities is positive: $A>0$. When the initial mortality rate is high enough, there is full annuitization: $A>0$ and $S^{h}=S^{s}=0$. When the initial mortality rate is low enough, there is partial annuitization for $\theta M>0$.

The meaning of $S^{h} \geq S^{s}=0$ in Proposition 1 is that non-annuitized savings in this model do not exceed the medical expense when falling sick. That is, nonannuitized savings in this model with mortality risks are precautionary savings in nature. Given the timing of events in this model, an agent has to choose annuitized and non-annuitized savings before knowing for sure whether they become sick in the first period. If he or she remains healthy throughout the first period, non-annuitized savings will be carried on into the second period. However, if he or she falls sick, non-annuitized savings will be fully terminated to pay for the medical expense. In the case that the agent does not make non-annunitized saving (i.e. $S^{h}=0$ ) but he or she turns out to be in poor health, the healthcare cost will be financed at the expenses of the consumption in period 1 . Therefore, the planned (but not necessarily the actual) consumption in period 1 must be bigger than $\theta M$. 
The intuition for the level of annuitization in Proposition 1 is twofold. First, since the rate of return on annuity savings is greater than that on non-annuitized savings, i.e. $\alpha>1+r$, there is a tendency for full annuitization as was well-known in the literature. Second, facing uncertainties about health status and medical expenses, there is a tendency for partial annuitization. Non-annuitized or precautionary savings are more flexible and more liquid than annuitized savings to meet uncertain and uninsurable expenses. When mortality (longevity) is high (low), the rate dominance in favor of annuities is high and hence agents fully annuitize their savings. When mortality (longevity) is low (high), the rate dominance fades away relative to the precaution against the morbidity risk, and therefore agents only annuitize a portion, rather than all, of their savings.

One may wonder whether the optimal solution is unique. We establish this below and relegate the proof to the Appendix.

Proposition 2. The optimal solution is unique.

The uniqueness of the optimal solution paves ways for us to carry out comparative static analysis and numerical simulations in the rest of this section. One of the central issues is to find out the degree of annuitization. With a unit mass of the population at the beginning of period 1 , the value of $A$ is also the total value of annuities. On the other hand, the value of non-annuity saving is only possible to be positive with good health, and thus the total value of non-annuity savings is equal to $(1-\pi) S^{h}+\pi S^{s}=(1-\pi) S^{h}$. Therefore, the ratio of annuity to total savings (annuity and non-annuity together) for this population is equal to $A /\left[(1-\pi) S^{h}+A\right]$, which is the measure of annuitization of savings we will use in this model. 
We now deal with comparative static analysis, starting with variations in the probability of morbidity.

Proposition 3. Annuitized savings decrease with the morbidity probability and medical expenses; and non-annuitized savings, if non-zero, increase with the morbidity probability and medical expenses.

The proof of the proposition is placed in the Appendix. The result in Proposition 3 is very intuitive. If either the morbidity probability or the medical expense becomes higher, so does the demand for liquid assets to pay for the medical expenses. As a result, agents will substitute non-annuitized savings for annuitized ones because the former can be easily terminated by forgoing the interest income. An important implication of Proposition 3 is that the degree of annuitization decreases with the degree of the morbidity risk or the associated medical costs to agents. Moreover, the result suggests that the rising healthcare costs in many countries in the last two decades on the one hand and the cut-back in the public subsidy on the other should have reduced the degree of annuitization.

We now consider how mortality affects annuitized and non-annuitized savings. In the case when non-annuitized savings are at the corner solution (zero), the response of annuitized savings to a change in mortality is given below. We state the following result and relegate the proof to the Appendix.

Proposition 4. If $S^{h}=S^{s}=0$, annuitized savings decrease with the mortality probability.

The result in Proposition 4 is also intuitive. Note that a negative response of annuities to a rise in mortality means that a decline in mortality or a rise in longevity 
raises annuitized savings. As in the literature, rising longevity calls for more savings because the demand for consumption in the later old age rises. When agents annuitize their savings fully at the optimum, a rise in longevity raises annuitized savings.

When non-annuitized savings with good health are positive, the responses of both types of savings to a change in mortality are given below (see the proof in the Appendix).

Proposition 5. Consider the case with $S^{h}>S^{s}=0$. When the initial mortality rate is high enough, annuitized savings decrease with the mortality rate but non-annuitized savings remain at zero. When the initial mortality rate is low enough, annuitized savings may decrease or increase with the mortality rate but for a high enough morbidity rate non-annuitized savings decrease with the mortality rate.

According to Proposition 5, the effects of a change in mortality on annuitized and non-annuitized savings depend on initial mortality and morbidity. To understand this, first note that $\partial A / \partial q<0$ and $\partial S^{h} / \partial q<0$ mean that a decline in mortality will raise annuitized and non-annuitized savings. When initial mortality is high, the annuity rate of return is much higher than the rate of return on non-annuitized savings and thus we expect full annuitization as given in Proposition 1. Starting from this full annuitization situation, a decline in mortality or a rise in longevity, which calls for more savings, will raise annuitized savings and force non-annuitized savings to stay at zero. The dominance in return by annuitized over non-annuitized savings diminishes as mortality falls further, while the precautionary motive for non-annuitized savings to cope with the morbidity risk becomes stronger. Eventually, at a certain mortality rate a further rise (fall) in longevity (mortality) will lead to a rise in non-annuitized savings as long as the rate of morbidity is high enough; and the response of annuitized 
savings becomes ambiguous. When mortality continues to fall beyond this stage, the return dominance by annuities fades and we would expect non-annuitized savings to grow faster than annuitized savings. This is because non-annuitized savings are more flexible than annuitized savings to cope with both the longevity risk and morbidity risk at the same time. In short, when initial mortality is high, annuitization remains full in the process of rising longevity; when initial mortality is low, annuitization becomes partial and is likely to fall in the process of rising longevity.

\section{Numerical example}

To obtain quantitative assessments of how mortality or survival rates affect annuitization, we need a specific assumption of the utility function. For this purpose, we assume a typical one used in the literature with a constant coefficient of relative risk aversion, i.e. $U(C)=\left(C^{1-\sigma}-1\right) /(1-\sigma), \sigma>0$ where $\sigma$ indicates the degree of relative risk aversion. The parameterization in the reported example is as follows. First, we assume that one period corresponds to 15 years. Second, we normalize the size of initial wealth $W$ to unity. The rest of the parameterization is: $r=1.0789$ (or $5 \%$ annually), $M=0.5$ (half of initial wealth), $\theta=0.68$ (a nearly $1 / 3$ subsidy rate), $\pi=0.5$ (i.e. 50-50 the chance to be sick or healthy), and $\sigma=3$ (in line with the literature).

The numerical example in Figure 1 shows two different patterns of the relationships between the change in annuitization and rising longevity (simply regarded as the survival rate $1-q$ ), depending on the initial level of longevity. When the survival rate $1-q$ is very low initially (at 0.1 ), there is full annuitization that remains in the process of rising longevity to some range of the survival rate. When the survival rate becomes high enough (above 0.36), there is partial annuitization (i.e. 
non-annuitized saving becomes positive) and the level of annuitization falls in the process of rising longevity. However, the amount of annuities is always increasing in the process of rising longevity in this example. Though initially zero, non-annuitized saving becomes positive and rises faster than annuities in a later stage of this process of rising longevity. The intuition is that when longevity is higher, there is increased demand for consumption in the second period, which thins out the provision of the given initial wealth for the first period and hence makes the medical cost a bigger concern.

Even though the idea that uncertain health and medical expenses may cause partial annuitization is simple and already known in the literature, the exact implication has not yet been well explored in existing studies. From Proposition 1, we learn that the amount of non-annuitized saving is made just to the point that it is enough to cope with the medical expense if having poor health, as the simple idea would suggest. In essence, non-annuitized saving is precautionary saving in nature. However, Proposition 1 opens two possibilities for either partial or full annuitization except in the extreme cases with high or low mortality. In our numerical example, we have illustrated that when longevity is initially low, it is optimal to have full annuitization and no precautionary saving at all, despite the chance for poor health and the subsequent lumpy medical cost. When longevity rises beyond a certain level, precautionary saving becomes positive and rises, and thus annuitization falls. The turning point of the survival rate at 0.36 (corresponding to a mortality rate at 0.64 ) for that age group is lower than the realistic figures in developed countries today, ${ }^{7}$ indicating that rising longevity is most likely to drive down annuitization in these countries.

\footnotetext{
${ }^{7}$ In the U.S., year 2000, those who are at the age of 60 have a probability of 0.58 to reach the age of 80.
} 

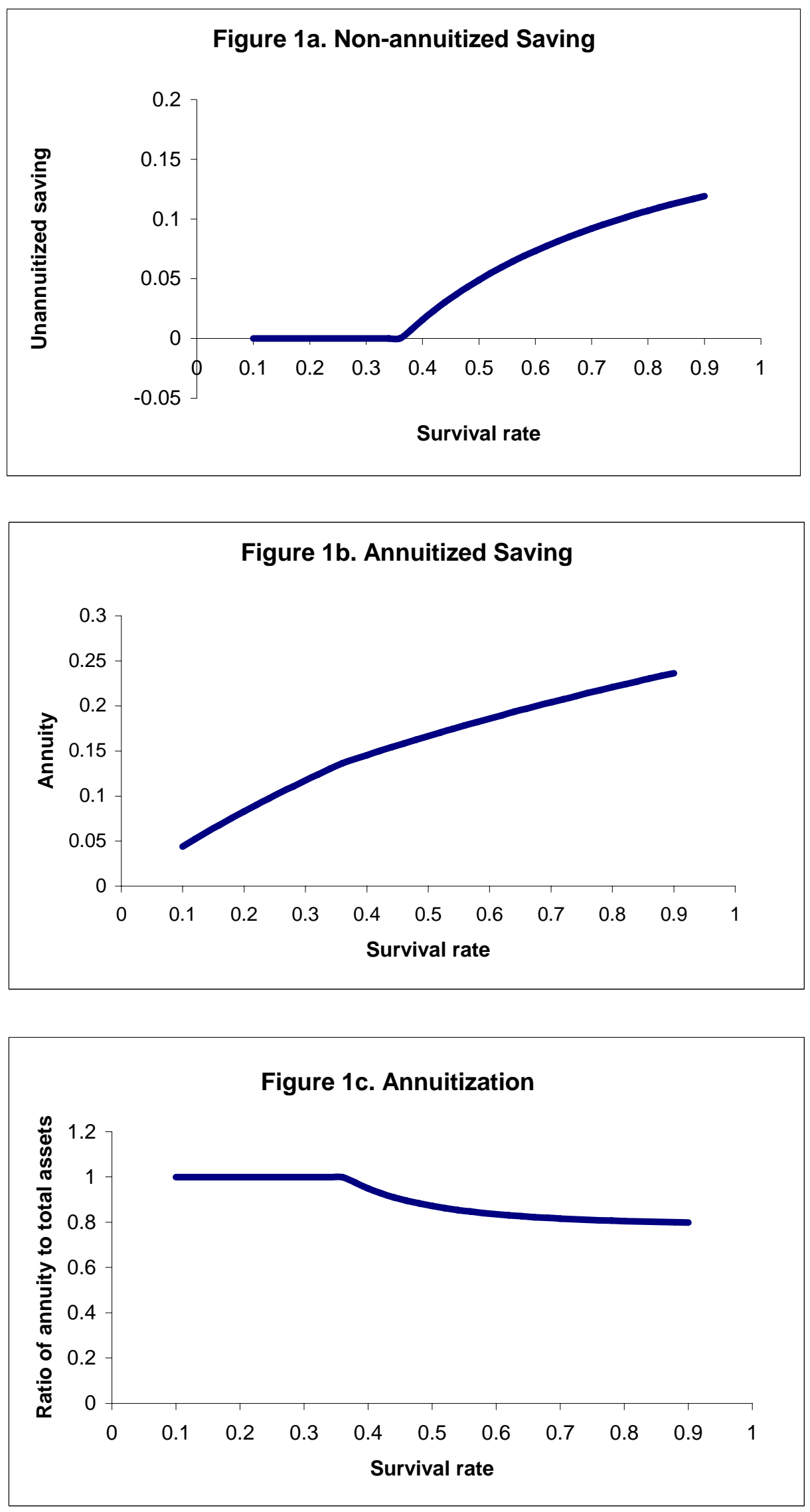


\section{Extension with the dependence of mortality on morbidity}

In this section, we consider a natural case that mortality and morbidity risks are positively correlated; that is, a person who is healthy in period 1 will have a higher probability of surviving to period 2 .

More precisely, for persons who are respectively in good and poor health in period 1 , their probabilities of dying at the end of the period are equal to $q^{h}$ and $q^{s}$, with $q^{s}>q^{h}$. Suppose the proportion of the population that are in good health status is equal to $\beta<1$. Therefore, the population wide probability of dying is given by

$$
q=\beta q^{h}+(1-\beta) q^{s}
$$

The expected utility of the agent at the beginning of period 1 is

$$
E_{t_{0}}(U(\cdot)) \equiv(1-\pi)\left[U\left(C_{1}^{h}\right)+\left(1-q^{h}\right) U\left(C_{2}^{h}\right)\right]+\pi\left[U\left(C_{1}^{s}\right)+\left(1-q^{s}\right) U\left(C_{2}^{s}\right)\right]
$$

The budget constraints remain the same as (3)-(6).

Proposition 6. Consider the case whereby mortality and morbidity risks are positively correlated. The amount of non-annuitized savings is equal to zero with poor health and is positive or zero with good health: $S^{h} \geq S^{s}=0$. Also, the amount of annuities is positive: $A>0$. When initial mortality is high enough, there is full annuitization: $A>$ 0 and $S^{h}=S^{s}=0$. When the initial mortality rate is low enough, there is partial annuitization for $\theta M>0$.

According to Proposition 6, this extension to condition survival on morbidity retains the results in the base model. We have also made progress in some other extensions such as allowing for healthy agents to continue working and for agents to leave bequests. These two issues are particularly important in that a lot of elderly people may choose to extend their working life (e.g. semi-retirement) as a response to 
rising longevity, and that bequests are a key channel of inter-generational wealth transfers. Due to the space limit, we have to leave the analysis of the extensions in a separate paper. Nevertheless, it is worthwhile to mention here that both extensions have further strengthened our results in explaining the thin voluntary annuity market in terms of uncertain healthcare expenses. In the first extension, if healthy agents opt to continue to work, any savings of their labor income must be in the form of nonannuitized saving as the annuity purchase decision has to be made before the health status is revealed. As a result, for the population as a whole, annuitization must fall. In the second extension, a bequest motive makes non-annuitized savings more attractive than annuities as the latter in general are not transferable to any beneficiaries other than the spouse. However, this result with a bequest motive may change to some extent if incorporating the fact that some annuities do allow room for bequests, such as in the form of a death benefit.

\section{Conclusion}

This paper contributes to the understanding of the offsetting forces on the annuitization of retirement savings. This issue is increasingly important because over recent years there has been being a shift from defined benefit (DB) plans to defined contribution (DC) plans amongst establishments of all size (Mitchell 2000). And there is clear evidence that people under DB plans tend to take up lump sum payments rather than pension payments upon their retirement. This phenomenon is in great contrast to the presumed great advantage of annuities over non-annuitized assets and has been begging for explanations. In this paper, we focus on a particular factor: uncertainties in health status and medical expenditure. 
We have considered two versions of a model that links annuitization to longevity. In both versions, we have shown the following: non-annuitized saving may be positive with good health but is turned into out-of-pocket payment for medical expenses with poor health. The amount of annuity purchased is always positive but annuitization becomes partial when the initial mortality rate becomes low enough. We have begun with a simple version with a morbidity risk in the first period of old age and a longevity risk for one to survive through the second period. In this simple version of the model, we have illustrated analytically and numerically that when longevity rises, annuitization is initially full for some range of low longevity levels, and then becomes partial and may eventually fall. An extension to condition mortality on morbidity generates similar results. 


\section{Appendix}

Proof of Proposition 1. The existence of an optimal solution to the problem is assured because (i) the objective function is continuous and at least twice differentiable and (ii) all of the choice variables lie in bounded and closed sets. The main task in this proof is about the conditions under which a variable takes a corner or interior solution. In doing so, we first show $S^{h} \geq S^{s}$. Suppose the opposite: $S^{h}<S^{s}$. Combining it with the budget constraints (3)-(6), it follows: $C_{2}^{s}>C_{2}^{h}$ and $C_{1}^{s}<C_{1}^{h}$. Given the assumption of $U^{\prime \prime}(\cdot)<0$, we then have $U^{\prime}\left(C_{2}^{s}\right)<U^{\prime}\left(C_{2}^{h}\right)$ and $U^{\prime}\left(C_{1}^{s}\right)>U^{\prime}\left(C_{1}^{h}\right)$. Combining it with the non-positive net marginal benefit of $S^{h}$, i.e. $\left[-U^{\prime}\left(C_{1}^{h}\right)+(1-q)(1+r) U^{\prime}\left(C_{2}^{h}\right)\right] \leq 0$, in the optimal condition (8) leads to

$$
U^{\prime}\left(C_{1}^{s}\right)>U^{\prime}\left(C_{1}^{h}\right) \geq(1-q)(1+r) U^{\prime}\left(C_{2}^{h}\right)>(1-q)(1+r) U^{\prime}\left(C_{2}^{s}\right)
$$

Here, $U^{\prime}\left(C_{1}^{s}\right)>(1-q)(1+r) U^{\prime}\left(C_{2}^{s}\right)$ implies $S^{s}=0$ and hence $S^{s}>S^{h}$ cannot hold given that $S^{h} \geq 0$, leading to a contradiction. Thus, $S^{h} \geq S^{s}$. For $\theta M>0$, the converse argument cannot hold in general because $S^{h}>S^{s}$ only implies $C_{2}^{h}>C_{2}^{s}$ but not necessarily $C_{1}^{h}<C_{1}^{s}$.

Second, we show $S^{s}=0$. Suppose $S^{s}>0$. Then, from (7), (8) and $S^{h} \geq S^{s}$, we have $\left[-U^{\prime}\left(C_{1}^{h}\right)+(1-q)(1+r) U^{\prime}\left(C_{2}^{h}\right)\right]=0$ and $\left[-U^{\prime}\left(C_{1}^{s}\right)+(1-q)(1+r) U^{\prime}\left(C_{2}^{s}\right)\right]=0$. Substituting them into (9) leads to

$$
\begin{aligned}
& \partial E_{t_{0}}(U(\cdot)) / \partial A=(1-\pi)\left[-U^{\prime}\left(C_{1}^{h}\right)+(1-q) U^{\prime}\left(C_{2}^{h}\right) \alpha\right] \\
&+\pi\left[-U^{\prime}\left(C_{1}^{s}\right)+(1-q) U^{\prime}\left(C_{2}^{s}\right) \alpha\right] \\
&=(1-q)\left[(1-\pi) U^{\prime}\left(C_{2}^{h}\right)+\pi U^{\prime}\left(C_{2}^{s}\right)\right][-(1+r)+\alpha] \\
&> 0
\end{aligned}
$$


since $-(1+r)+\alpha=-(1+r)+(1+r) /(1-q)>0$ according to (1) and since the marginal utility functions are positive. Here, the implication $\partial E_{t_{0}}(U(\cdot)) / \partial A>0$ violates (9). Thus, $S^{s}=0$ has to hold.

The result $A>0$ is straightforward because $A=0$ along with $S^{s}=0$ would imply $C_{2}^{s}=0$ and hence an infinitely large $U^{\prime}\left(C_{2}^{s}\right)$, which violates $\left[-U^{\prime}\left(C_{1}^{s}\right)+(1-q)(1+r) U^{\prime}\left(C_{2}^{s}\right)\right] \leq 0$ in general because of the Inada condition $U^{\prime}\left(C_{j}^{i}\right) \rightarrow \infty$ if $C_{j}^{i} \rightarrow 0$

Further, from the first-order conditions associated with $S^{i}$ for $i=h, s$, the marginal utility gained from such savings, $(1-q) U^{\prime}\left(C_{2}^{i}\right)$, becomes zero if $q \rightarrow 1$ for any positive $A$ that leads to a positive yet finite $U^{\prime}\left(C_{2}^{i}\right)$ for $i=h, s$. Consequently, the net marginal benefit of such savings must be strictly negative and therefore $S^{s}=S^{h}=0$. On the other hand, as $q \rightarrow 1$ the marginal utility gain of $A$, $\alpha(1-q) U^{\prime}\left(C_{2}^{i}\right)=(1+r) U^{\prime}\left(C_{2}^{i}\right)$, can avoid approaching zero if $A$ is chosen to be proportional to $1-q$ by observing that $C_{2}^{i}=\alpha A=A(1+r) /(1-q)$ for $S^{s}=S^{h}=0$. Note that $A$ cannot take a corner solution as $q \rightarrow 1$ given that $S^{s}=S^{h}=0$, because if it does then $C_{2}^{i} \rightarrow 0$ and hence $U^{\prime}\left(C_{2}^{i}\right) \rightarrow \infty$ under the Inada condition. The last point is the rate dominance of annuities in the first-order conditions (7)-(9): given the finite marginal cost of $A$ and $S$, when $q \rightarrow 1$ the marginal benefit of any finite level $C_{2}^{i}$ will be higher if financed by $A$ than by $S$. Thus, for a high enough initial mortality rate $q$, there is full annuitization.

Finally, we show that for $\theta M>0$ there is partial annuitization when $q$ is sufficiently small. Suppose that there is full annuitization for all values of $q$. Then, 
$S^{h}=S^{s}=0$ and hence $C_{2}^{s}=C_{2}^{h}$ from the budget constraints. For $\theta M>0$, it follows that $C_{1}^{s}<C_{1}^{h}$ and therefore $U^{\prime}\left(C_{1}^{s}\right)>U^{\prime}\left(C_{2}^{h}\right)$ under the assumption $U^{\prime \prime}(\cdot)<0$. From the first-order conditions, we must thus have $\partial E_{t_{0}}(U(\cdot)) / \partial S^{s} / \pi<\partial E_{t_{0}}(U(\cdot)) / \partial S^{h} /(1-\pi)$, implying $\partial E_{t_{0}}(U(\cdot)) / \partial S^{s}<0$ since $\partial E_{t_{0}}(U(\cdot)) / \partial S^{h} \leq 0$. Using the first-order conditions with respect to $A$ and $S^{h}$, let us construct the difference in their net gains in marginal utility:

$$
\frac{\partial E_{t_{0}}(U(\cdot))}{\partial S^{h}}-\frac{\partial E_{t_{0}}(U(\cdot))}{\partial A}=-q(1-\pi)(1+r) U^{\prime}\left(C_{2}^{h}\right)-\pi\left[-U^{\prime}\left(C_{1}^{s}\right)+(1+r) U^{\prime}\left(C_{2}^{s}\right)\right]
$$

under $\alpha=(1+r) /(1-q)$. Note that, when $q$ approaches zero, the first term on the right-hand side approaches zero and the second term approaches $-\partial E_{t_{0}}(U(\cdot)) / \partial S^{s}$. Combining the arguments together, for $\theta M>0$ we must have

$$
\lim _{q \rightarrow 0} \frac{\partial E_{t_{0}}(U(\cdot))}{\partial S^{h}}-\frac{\partial E_{t_{0}}(U(\cdot))}{\partial A}=-\pi \frac{\partial E_{t_{0}}(U(\cdot))}{\partial S^{s}}>0 .
$$

The fact $A>0 \forall q \in(0,1)$ implies $\partial E_{t_{0}}(U(\cdot)) / \partial A=0$ by the associated first-order condition. It follows $\partial E_{t_{0}}(U(\cdot)) / \partial S^{h}>0$, which violates the associated first-order condition. Thus, $S^{h}>0$ for $\theta M>0$ if $q$ is sufficiently small. In other words, there is partial annuitization under these conditions. Q.E.D.

Proof of Proposition 2. When $q$ is large such that there is full annuitization, the proof of the uniqueness of the solution starts from the fact that $A>0$ implies $\partial E_{t_{0}}(U) / \partial A=0$. Further, it is based on the fact that the net gain in marginal utility of annuity purchase is monotonically decreasing in $A$ : 


$$
\begin{gathered}
\frac{\partial^{2} E_{t_{0}}(U(\cdot))}{\partial A^{2}}=(1-\pi)\left[U^{\prime \prime}\left(C_{1}^{h}(A)\right)+\alpha^{2}(1-q) U^{\prime \prime}\left(C_{2}^{h}(A)\right)\right]+ \\
\pi\left[U^{\prime \prime}\left(C_{1}^{s}(A)\right)+\alpha^{2}(1-q) U^{\prime \prime}\left(C_{2}^{s}(A)\right)\right]<0
\end{gathered}
$$

implying that there is a unique positive value of $A$ to satisfy $\partial E_{t_{0}}(U) / \partial A=0$.

When $q$ is small such that there is partial annuitization, the proof is more involved since $S^{h}>0$ as well. Here, $A>0$ and $S^{h}>0$ imply that $\partial E_{t_{0}}(U) / \partial A=0$ and $\partial E_{t_{0}}(U) / \partial S^{h}=0$. Suppose the optimal solution is not unique, based on the budget constraints and the first-order conditions. Let us say there are two optimal solutions $\left(A^{*}, S^{*}\right)$ and $\left(A^{* *}, S^{* *}\right)$ with $A^{* *}>A^{*}$. We make the argument in a few steps. First, the budget constraints imply $C_{1}^{s}\left(A^{* *}\right)<C_{1}^{s}\left(A^{*}\right)$ and $C_{2}^{s}\left(A^{* *}\right)>C_{2}^{s}\left(A^{*}\right)$ and therefore $U^{\prime}\left(C_{1}^{s}\left(A^{* *}\right)\right)>U^{\prime}\left(C_{1}^{s}\left(A^{*}\right)\right)$ and $U^{\prime}\left(C_{2}^{s}\left(A^{* *}\right)\right)<U^{\prime}\left(C_{2}^{s}\left(A^{*}\right)\right)$. Second, the two first-order conditions together by substitution lead to:

$$
(1-\pi)(1-q) U^{\prime}\left(C_{2}^{h}\left(A^{i}, S^{i}\right)\right)[\alpha-(1+r)]=\pi\left[U^{\prime}\left(C_{1}^{s}\left(A^{i}, S^{i}\right)\right)-\alpha(1-q) U^{\prime}\left(C_{2}^{s}\left(A^{i}, S^{i}\right)\right)\right]
$$

where $i$ refers to either $*$ or $* *$. Combining the first step with the second, the righthand side of the last equation must be greater with $\left(A^{* *}, S^{* *}\right)$ than with $\left(A^{*}, S^{*}\right)$ and so too must be the left-hand side under the rate dominance $a>1+r$. That is, $U^{\prime}\left(C_{2}^{h}\left(A^{* *}, S^{* *}\right)\right)>U^{\prime}\left(C_{2}^{h}\left(A^{*}, S^{*}\right)\right)$, which, together with $\partial E_{t_{0}}(U) / \partial S^{h}=0$, implies $U^{\prime}\left(C_{1}^{h}\left(A^{* *}, S^{* *}\right)\right)>U^{\prime}\left(C_{1}^{h}\left(A^{*}, S^{*}\right)\right)$.

Observe that, $U^{\prime}\left(C_{2}^{h}\left(A^{* *}, S^{* *}\right)\right)>U^{\prime}\left(C_{2}^{h}\left(A^{*}, S^{*}\right)\right)$ and $U^{\prime \prime}<0$ lead to $C_{2}^{h}\left(A^{* *}, S^{* *}\right)<C_{2}^{h}\left(A^{*}, S^{*}\right)$, implying $\alpha A^{*}+(1+r) S^{*}>\alpha A^{* *}+(1+r) S^{* *}$ according to the budget constraint. Rewrite it as (a): $\alpha\left(A^{*}-A^{* *}\right)>(1+r)\left(S^{* *}-S^{*}\right)$. Similarly, $U^{\prime}\left(C_{1}^{h}\left(A^{* *}, S^{* *}\right)\right)>U^{\prime}\left(C_{1}^{h}\left(A^{*}, S^{*}\right)\right)$ and $U^{\prime \prime}<0$ lead to $C_{1}^{h}\left(A^{* *}, S^{* *}\right)<C_{1}^{h}\left(A^{*}, S^{*}\right)$, implying $A^{*}+S^{*}<A^{* *}+S^{* *}$ according to the budget constraint. Rewrite it as (b): 
$S^{* *}-S^{*}>A^{*}-A^{* *}$. Substitute (b) into (a) gives us $\alpha\left(A^{*}-A^{* *}\right)>(1+r)\left(A^{*}-A^{* *}\right)$, implying $A^{*}[\alpha-(1+r)]>A^{* *}[\alpha-(1+r)]$. Given that $\alpha>1+r$, we must have $A^{*}>A^{* *}$, presenting a contradiction. Therefore, the optimal solution for $A$ must be unique, i.e. $A^{* *}=A^{*}$. Further, given any unique optimal solution for $A$, the optimal solution for $S^{h}$ must be unique as well because its net marginal gain in utility must equal zero and must be decreasing in $S^{h}$. Q.E.D.

Proof of Proposition 3. First we prove that $\partial A / \partial \pi<0$, and $\partial S^{h} / \partial \pi>0$ if $S^{h}>0$. If $S^{h}=S^{s}=0$, since $A>0$, from (1) and (9) we have

$$
(1-\pi) U^{\prime}\left(C_{1}^{h}\right)+\pi U^{\prime}\left(C_{1}^{s}\right)=(1-\pi)(1+r) U^{\prime}\left(C_{2}^{h}\right)+\pi(1+r) U^{\prime}\left(C_{2}^{s}\right)
$$

The budget constraints (3)-(6) become: $C_{1}^{s}=W-\theta M-A, C_{1}^{h}=W-A$, and $C_{2}^{s}=C_{2}^{h}=\alpha$ A. Substituting these into (12) gives

$$
(1-\pi) U^{\prime}\left(C_{1}^{h}\right)+\pi U^{\prime}\left(C_{1}^{s}\right)=(1+r) U^{\prime}\left(C_{2}^{h}\right)
$$

Differentiating (13) with respect to $\pi$ obtains

$$
\frac{\partial A}{\partial \pi}=\frac{U^{\prime}\left(C_{1}^{s}\right)-U^{\prime}\left(C_{1}^{h}\right)}{(1-\pi) U^{\prime \prime}\left(C_{1}^{h}\right)+\pi U^{\prime \prime}\left(C_{1}^{s}\right)+(1+r)^{2} U^{\prime \prime}\left(C_{2}^{h}\right) /(1-q)}<0
$$

as $C_{1}^{s}<C_{1}^{h} \Rightarrow U^{\prime}\left(C_{1}^{s}\right)>U^{\prime}\left(C_{1}^{h}\right)$.

If $S^{h}>S^{s}=0$, (12) still holds. From (8), we obtain

$$
U^{\prime}\left(C_{1}^{h}\right)=(1-q)(1+r) U^{\prime}\left(C_{2}^{h}\right)
$$

The budget constraints (3)-(6) become: $C_{1}^{s}=W-\theta M-A, C_{1}^{h}=W-A-S^{h}$, $C_{2}^{s}=\alpha A$, and $C_{2}^{h}=\alpha A+(1+r) S^{h}$. 
Differentiating (12) and (15) with respect to $\pi$ and making use of the budget constraints, we obtain

$$
\left[\begin{array}{c}
\partial A / \partial \pi \\
\partial S^{h} / \partial \pi
\end{array}\right]=\frac{1}{\Delta_{a}}\left[\begin{array}{cc}
a_{22} & -a_{21} \\
-a_{12} & a_{11}
\end{array}\right]\left[\begin{array}{l}
x_{1} \\
x_{2}
\end{array}\right]
$$

where

$$
\begin{aligned}
a_{11}= & U^{\prime \prime}\left(C_{1}^{h}\right)+(1+r)^{2} U^{\prime \prime}\left(C_{2}^{h}\right)<0, \\
a_{12}= & U^{\prime \prime}\left(C_{1}^{h}\right)+(1-q)(1+r)^{2} U^{\prime \prime}\left(C_{2}^{h}\right)<0, \\
a_{21}= & (1-\pi) U^{\prime \prime}\left(C_{1}^{h}\right)+\frac{(1-\pi)(1+r)^{2}}{1-q} U^{\prime \prime}\left(C_{2}^{h}\right)+\pi U^{\prime \prime}\left(C_{1}^{s}\right)+\frac{\pi(1+r)^{2}}{1-q} U^{\prime \prime}\left(C_{2}^{s}\right)<0, \\
a_{22}= & (1-\pi)\left[U^{\prime \prime}\left(C_{1}^{h}\right)+(1+r)^{2} U^{\prime \prime}\left(C_{2}^{h}\right)\right]<0, \\
\Delta_{a}= & a_{11} a_{22}-a_{12} a_{21} \\
= & -\frac{q^{2}}{1-q}(1-\pi)(1+r)^{2} U^{\prime \prime}\left(C_{1}^{h}\right) U^{\prime \prime}\left(C_{2}^{h}\right) \\
& -\left[U^{\prime \prime}\left(C_{1}^{h}\right)+(1-q)(1+r)^{2} U^{\prime \prime}\left(C_{2}^{h}\right)\right]\left[\pi U^{\prime \prime}\left(C_{1}^{s}\right)+\pi \frac{(1+r)^{2}}{1-q} U^{\prime \prime}\left(C_{2}^{s}\right)\right]<0 \\
x_{1}= & 0, \\
x_{2}= & {\left[U^{\prime}\left(C_{1}^{s}\right)-U^{\prime}\left(C_{1}^{h}\right)\right]+(1+r)\left[U^{\prime}\left(C_{2}^{s}\right)-U^{\prime}\left(C_{2}^{h}\right)\right]>0 . }
\end{aligned}
$$

Now, we obtain $\partial A / \partial \pi=-a_{21} x_{2} / \Delta_{a}<0$ and $\partial S^{h} / \partial \pi=a_{11} x_{2} / \Delta_{a}>0$.

Second, we prove that $\partial A / \partial(\theta M)<0$, and $\partial S^{h} / \partial(\theta M)>0$ if $S^{h}>0$. Following a similar procedure as before, we can obtain that

$$
\left[\begin{array}{c}
\partial A / \partial(\theta M) \\
\partial S^{h} / \partial(\theta M)
\end{array}\right]=\frac{1}{\Delta_{a}}\left[\begin{array}{cc}
a_{22} & -a_{21} \\
-a_{12} & a_{11}
\end{array}\right]\left[\begin{array}{l}
y_{1} \\
y_{2}
\end{array}\right]
$$

where the matrix with elements $a_{i j}$ is the same as the one in (16), and where

$$
y_{1}=0 \text {, and }
$$




$$
y_{2}=-\pi U^{\prime \prime}\left(C_{1}^{s}\right)>0 \text {. }
$$

Now, we obtain $\partial A / \partial(\theta M)=-a_{21} y_{2} / \Delta_{a}<0$ and $\partial S^{h} / \partial(\theta M)=a_{11} y_{2} / \Delta_{a}>0$. Q.E.D.

Proof of Proposition 4. Differentiate (12) with respect to $q$ to obtain

$$
\frac{\partial A}{\partial q}=\frac{-(1+r)^{2} U^{\prime \prime}\left(C_{2}^{h}\right)}{\left[(1-\pi) U^{\prime \prime}\left(C_{1}^{h}\right)+\pi U^{\prime \prime}\left(C_{1}^{s}\right)\right](1-q)^{2}+(1+r)^{2}(1-q) U^{\prime \prime}\left(C_{2}^{h}\right)}<0
$$

The result follows. Q.E.D.

Proof of Proposition 5. Differentiate (12) and (15) with respect to $q$ to obtain

$$
\left[\begin{array}{c}
\partial A / \partial q \\
\partial S^{h} / \partial q
\end{array}\right]=\frac{1}{\Delta_{a}}\left[\begin{array}{cc}
a_{22} & -a_{21} \\
-a_{12} & a_{11}
\end{array}\right]\left[\begin{array}{l}
z_{1} \\
z_{2}
\end{array}\right]
$$

where the matrix with elements $a_{i j}$ is the same as that used in (16) and where

$$
\begin{aligned}
z_{1} & =(1+r) U^{\prime}\left(C_{2}^{h}\right)-\frac{(1+r)^{2} A}{1-q} U^{\prime \prime}\left(C_{2}^{h}\right) \\
& =-\frac{(1+r) C_{2}^{h} U^{\prime \prime}\left(C_{2}^{h}\right)}{\sigma}-\frac{(1+r)^{2} A}{1-q} U^{\prime \prime}\left(C_{2}^{h}\right)>0, \\
z_{2} & =-\frac{(1-\pi)(1+r)^{2} A}{(1-q)^{2}} U^{\prime \prime}\left(C_{2}^{h}\right)-\frac{\pi(1+r)^{2} A}{(1-q)^{2}} U^{\prime \prime}\left(C_{2}^{s}\right)>0 .
\end{aligned}
$$

Here, $\sigma=-C U^{\prime \prime}(C) / U^{\prime}(C)$ is the degree of relative risk aversion which can be a constant with a CRRA or CES utility function. From these results, we have

$$
\begin{gathered}
a_{22} z_{1}-a_{21} z_{2}=-(1-\pi)(1+r)\left[U^{\prime \prime}\left(C_{1}^{h}\right)+(1+r)^{2} U^{\prime \prime}\left(C_{2}^{h}\right)\right]\left[\frac{C_{2}^{h}}{\sigma}+\frac{(1+r) A}{1-q}\right] \\
U^{\prime \prime}\left(C_{2}^{h}\right)+\left[(1-\pi) U^{\prime \prime}\left(C_{1}^{h}\right)+\pi U^{\prime \prime}\left(C_{1}^{s}\right)+\frac{(1-\pi)(1+r)^{2}}{1-q} U^{\prime \prime}\left(C_{2}^{h}\right)+\right. \\
\left.\frac{\pi(1+r)^{2}}{1-q} U^{\prime \prime}\left(C_{2}^{s}\right)\right]\left[(1-\pi) U^{\prime \prime}\left(C_{2}^{h}\right)+\pi U^{\prime \prime}\left(C_{2}^{s}\right)\right] \frac{A(1+r)^{2}}{(1-q)^{2}}
\end{gathered}
$$


which is ambiguous in general. It is positive if $q$ is sufficiently large or $\pi$ is sufficiently large. Since $\partial A / \partial q=\left(a_{22} z_{1}-a_{21} z_{2}\right) / \Delta_{a}$ with $\Delta_{a}<0$, under the same condition, $\partial A / \partial q<0$.

Similarly, we have $\partial S^{h} / \partial q=\left(a_{11} z_{2}-a_{12} z_{1}\right) / \Delta_{a}$ where

$$
\begin{aligned}
a_{11} Z_{2}- & a_{12} Z_{1}=-\left[U^{\prime \prime}\left(C_{1}^{h}\right)+(1+r)^{2} U^{\prime \prime}\left(C_{2}^{h}\right)\right]\left[(1-\pi) U^{\prime \prime}\left(C_{2}^{h}\right)+\pi U^{\prime \prime}\left(C_{2}^{s}\right)\right] \\
& \frac{A(1+r)^{2}}{(1-q)^{2}}+(1+r)\left[(1-q)(1+r)^{2} U^{\prime \prime}\left(C_{2}^{h}\right)+U^{\prime \prime}\left(C_{1}^{h}\right)\right]\left[\frac{C_{2}^{h}}{\sigma} U^{\prime \prime}\left(C_{2}^{h}\right)\right. \\
& \left.+\frac{(1+r) A}{1-q} U^{\prime \prime}\left(C_{2}^{s}\right)\right]
\end{aligned}
$$

which is also ambiguous. It is negative and hence $\partial S^{h} / \partial q>0$ for a large enough $q$. This is unlikely to occur because when $q$ is large enough, there is a corner solution for non-annuitized savings under Proposition 1. However, it does add pressure for $S$ to remain cornered when $q$ falls from a high level. If $q \rightarrow 0$, on the other hand, then

$$
\begin{aligned}
a_{11} z_{2} & -a_{12} z_{1} \rightarrow(1-\pi) A(1+r)^{2}\left[U^{\prime \prime}\left(C_{2}^{s}\right)-U^{\prime \prime}\left(C_{2}^{h}\right)\right]\left[U^{\prime \prime}\left(C_{1}^{h}\right)+(1+r)^{2} U^{\prime \prime}\left(C_{2}^{h}\right)\right] \\
+ & {\left[U^{\prime \prime}\left(C_{1}^{h}\right)+(1+r)^{2} U^{\prime \prime}\left(C_{2}^{h}\right)\right] U^{\prime \prime}\left(C_{2}^{h}\right) C_{2}^{h} \frac{(1+r)}{\sigma} }
\end{aligned}
$$

which is positive and hence $\partial S^{h} / \partial q<0$ when $\pi$ is large enough. Q.E.D.

Proof of Proposition 6. The Kuhn-Tucker optimal conditions are:

$$
\begin{gathered}
\frac{\partial E_{t_{0}}(U(\cdot))}{\partial S^{s}}=\pi\left[-U^{\prime}\left(C_{1}^{s}\right)+\left(1-q^{s}\right)(1+r) U^{\prime}\left(C_{2}^{s}\right)\right] \leq 0, \quad S^{s} \geq 0, \\
\frac{\partial E_{t_{0}}(U(\cdot))}{\partial S^{s}} S^{s}=0 ; \\
\frac{\partial E_{t_{0}}(U(\cdot))}{\partial S^{h}}=(1-\pi)\left[-U^{\prime}\left(C_{1}^{h}\right)+\left(1-q^{h}\right)(1+r) U^{\prime}\left(C_{2}^{h}\right)\right] \leq 0, \quad S^{h} \geq 0, \\
\frac{\partial E_{t_{0}}(U(\cdot))}{\partial S^{h}} S^{h}=0 ;
\end{gathered}
$$




$$
\begin{aligned}
& \frac{\partial E_{t_{0}}(U(\cdot))}{\partial A}=(1-\pi)\left[-U^{\prime}\left(C_{1}^{h}\right)+\alpha\left(1-q^{h}\right) U^{\prime}\left(C_{2}^{h}\right)\right]+ \\
& \quad \pi\left[-U^{\prime}\left(C_{1}^{s}\right)+\alpha\left(1-q^{s}\right) U^{\prime}\left(C_{2}^{s}\right)\right] \leq 0, \quad A \geq 0, \quad \frac{\partial E_{t_{0}}(U(\cdot))}{\partial A} A=0 .
\end{aligned}
$$

First, we prove that $S^{h} \geq S^{s}$. Suppose the opposite $S^{s}>S^{h}$ is true. Following the logic of the proof of Proposition 1 and noting that $1-q^{h}>1-q^{s}$, we have $U^{\prime}\left(C_{1}^{s}\right)>U^{\prime}\left(C_{1}^{h}\right) \geq\left(1-q^{h}\right)(1+r) U^{\prime}\left(C_{2}^{h}\right)>\left(1-q^{s}\right)(1+r) U^{\prime}\left(C_{2}^{h}\right)>\left(1-q^{s}\right)(1+r) U^{\prime}\left(C_{2}^{s}\right)$. This implies $S^{s}=0$ which contradicts $S^{s}>S^{h} \geq 0$.

Second, we prove that $S^{s}=0$ and $A>0$. Suppose that the opposite $S^{s}>0$ is true. Following the logic of the proof of Proposition 1, this implies that $\frac{\partial E_{t_{0}}(U(\cdot))}{\partial A}=(1-\pi)\left(1-q^{h}\right) U^{\prime}\left(C_{1}^{h}\right)(1+r)[-1+1 /(1-q)]+\pi\left(1-q^{s}\right) U^{\prime}\left(C_{1}^{s}\right)[-1+1 /(1-q)]>0$

This violate (24). Therefore, $S^{s}=0$ must hold. The proof of $A>0$ is identical to that in Proposition 1. The rest of the proof is similar to those in Proposition 1. Q.E.D. 


\section{References}

Auerbach, Alan; Gokhale, Jagadeesh; Sabelhaus, John; and Weil, David N. (2001). “The annuitization of Americans’ resources: a cohort analysis” in Laurence Kotlikoff (ed.) Essays on Saving, Bequests, Altruism, and Life-Cycle Planning, MIT Press, Cambridge, Massachusetts.

Brown, Jeffrey R. (1999). “Are the elderly really over-annuitized? New evidence on life insurance and bequests.” NBER Working Paper \#7193.

Brugiavini, Agar (1993). "Uncertainty resolution and the timing of annuity purchases.” Journal of Public Economics 50, 31-62.

Davidoff, Thomas; Brown, Jeffrey R.; and Diamond, Peter A. (2005). “Annuities and individual welfare.” American Economic Review 95 (5), 1573-1590.

Doyle, Suzanne; Mitchell, Olivia S.; and Piggott, John (2004). “Annuity values in defined contribution retirement systems: Australia and Singapore compared.” Australian Economic Review 37 (4), 402-416.

Dushi, Irene, and Webb, Anthony (2004). "Household annuitization decisions: simulations and empirical analyses.” Journal of Pension Economics and Finance 3 (2), 109-143.

Friedman, Benjamin M.; and Warshawsky, Mark J. (1990). “The cost of annuities: implications for saving behavior and bequests.” Quarterly Journal of Economics 105 (1), 135-154.

Hubbard, R. G., J. Skinner, and S. P. Zeldes (1995). ”Precautionary saving and social insurance.” Journal of Political Economy 103 (2): 360-399.

Mitchell, Oliver. S. (2000). New Trends in Pension Benefit and Retirement Provisions. A Report to the Pension and Welfare Benefits Administration of the U.S. Department of Labor. 
Murtaugh, Christopher M.; Spillman, Brenda; and Warshawsky, Mark J. (2001). “In sickness and in health: an annuity approach to financing long-term care and retirement income.” Journal of Risk and Insurance 68 (2), 225-254.

De Nardi, Mariacristina; French, Eric; Jones, John Bailey (2006). “Differential mortality, uncertain medical expenses, and the saving of elderly singles” NBER Working Paper \#12554.

Palumbo, Michale. G. (1999). "Uncertain medical expenses and precautionary saving near the end of the life cycle.” Review of Economic Studies 66(2): 395-41.

Pebley, Anne R., and Rudkin, Laura L. (1999). “Grandparents caring for grandchildren: what do we know?” Journal of Family Issues 20(2), 218-242.

Philipson, Tomas J., and Becker, Gary S. (1998). “Old-age longevity and mortalitycontingent claims.” Journal of Political Economy 106 (3), 551-573.

Piggott, John; Valdez, Emiliano A.; and Dentzel, Bettina (2005). “The simple analytics of a pooled annuity fund.” Journal of Risk and Insurance 72 (3), 497-520.

Turra, Cassio M., and Mitchell, Olivia, S. (2004). “The impact of health status and out-of-pocket medical expenditures on annuity valuation.” PARC Working Papers Series, WPS 04-02.

von Gaudecker, Hans-Martin, and Weber, Carsten (2004). "Surprises in a growing market niche: an evaluation of the German private life annuities market.” Geneva Papers on Risk and Insurance: Issues and Practice 29 (3), 394-416.

Yaari, Menahem E. (1965). "Uncertain lifetime, life Insurance, and the theory of the consumer.” Review of Economic Studies 32 (2), 137-150. 


\section{CESifo Working Paper Series}

for full list see www.cesifo-group.org/wp

(address: Poschingerstr. 5, 81679 Munich, Germany, office@cesifo.de)

2024 Erkki Koskela and Ronnie Schöb, Tax Progression under Collective Wage Bargaining and Individual Effort Determination, June 2007

2025 Jay Pil Choi and Marcel Thum, The Economics of Politically Connected Firms, June 2007

2026 Jukka Pirttilä and Roope Uusitalo, Leaky Bucket in the Real World: Estimating Inequality Aversion Using Survey Data, June 2007

2027 Ruslan Lukach, Peter M. Kort and Joseph Plasmans, Strategic R\&D with Knowledge Spillovers and Endogenous Time to Complete, June 2007

2028 Jarko Fidrmuc, Neil Foster and Johann Scharler, Labour Market Rigidities, Financial Integration and International Risk Sharing in the OECD, June 2007

2029 Bernardina Algieri and Thierry Bracke, Patterns of Current Account Adjustment Insights from Past Experience, June 2007

2030 Robert Dur and Hein Roelfsema, Social Exchange and Common Agency in Organizations, June 2007

2031 Alexander Libman and Lars P. Feld, Strategic Tax Collection and Fiscal Decentralisation: The Case of Russia, June 2007

2032 Øystein Foros, Hans Jarle Kind and Greg Shaffer, Resale Price Maintenance and Restrictions on Dominant Firm and Industry-Wide Adoption, June 2007

2033 Jan K. Brueckner and Kurt Van Dender, Atomistic Congestion Tolls at Concentrated Airports? Seeking a Unified View in the Internalization Debate, June 2007

2034 Viet Do and Ngo Van Long, International Outsourcing under Monopolistic Competition: Winners and Losers, June 2007

2035 Nadia Fiorino and Roberto Ricciuti, Determinants of Direct Democracy, June 2007

2036 Burkhard Heer and Alfred Maussner, Inflation and Output Dynamics in a Model with Labor Market Search and Capital Accumulation, June 2007

2037 Konstantinos Angelopoulos, Jim Malley and Apostolis Philippopoulos, Public Education Expenditure, Growth and Welfare, June 2007

2038 Maarten Bosker, Steven Brakman, Harry Garretsen and Marc Schramm, Adding Geography to the New Economic Geography, June 2007 
2039 Steffen Henzel, Oliver Hülsewig, Eric Mayer and Timo Wollmershäuser, The Price Puzzle Revisited: Can the Cost Channel Explain a Rise in Inflation after a Monetary Policy Shock?, July 2007

2040 Rosario Crinò, Service Offshoring and White-Collar Employment, July 2007

2041 Carsten Hefeker and Michael Neugart, Labor Market Regulation and the Legal System, July 2007

2042 Bart Cockx and Muriel Dejemeppe, Is the Notification of Monitoring a Threat to the Unemployed? A Regression Discontinuity Approach, July 2007

2043 Alfons J. Weichenrieder, Profit Shifting in the EU: Evidence from Germany, July 2007

2044 Annika Alexius and Bertil Holmlund, Monetary Policy and Swedish Unemployment Fluctuations, July 2007

2045 Axel Dreher, Jan-Egbert Sturm and Jakob de Haan, Does High Inflation Cause Central Bankers to Lose their Job? Evidence Based on a New Data Set, July 2007

2046 Guglielmo Maria Caporale and Luis A. Gil-Alana, Long Run and Cyclical Dynamics in the US Stock Market, July 2007

2047 Alessandro Balestrino, It is a Theft but not a Crime, July 2007

2048 Daniel Becker and Michael Rauscher, Fiscal Competition in Space and Time: An Endogenous-Growth Approach, July 2007

2049 Yannis M. Ioannides, Henry G. Overman, Esteban Rossi-Hansberg and Kurt Schmidheiny, The Effect of Information and Communication Technologies on Urban Structure, July 2007

2050 Hans-Werner Sinn, Please Bring me the New York Times - On the European Roots of Richard Abel Musgrave, July 2007

2051 Gunther Schnabl and Christian Danne, A Role Model for China? Exchange Rate Flexibility and Monetary Policy in Japan, July 2007

2052 Joseph Plasmans, Jorge Fornero and Tomasz Michalak, A Microfounded Sectoral Model for Open Economies, July 2007

2053 Vesa Kanniainen and Panu Poutvaara, Imperfect Transmission of Tacit Knowledge and other Barriers to Entrepreneurship, July 2007

2054 Marko Koethenbuerger, Federal Tax-Transfer Policy and Intergovernmental PreCommitment, July 2007

2055 Hendrik Jürges and Kerstin Schneider, What Can Go Wrong Will Go Wrong: Birthday Effects and Early Tracking in the German School System, July 2007 
2056 Bahram Pesaran and M. Hashem Pesaran, Modelling Volatilities and Conditional Correlations in Futures Markets with a Multivariate t Distribution, July 2007

2057 Walter H. Fisher and Christian Keuschnigg, Pension Reform and Labor Market Incentives, July 2007

2058 Martin Altemeyer-Bartscher, Dirk T. G. Rübbelke and Eytan Sheshinski, Policies to Internalize Reciprocal International Spillovers, July 2007

2059 Kurt R. Brekke, Astrid L. Grasdal and Tor Helge Holmås, Regulation and Pricing of Pharmaceuticals: Reference Pricing or Price Cap Regulation?, July 2007

2060 Tigran Poghosyan and Jakob de Haan, Interest Rate Linkages in EMU Countries: A Rolling Threshold Vector Error-Correction Approach, July 2007

2061 Robert Dur and Klaas Staal, Local Public Good Provision, Municipal Consolidation, and National Transfers, July 2007

2062 Helge Berger and Anika Holler, What Determines Fiscal Policy? Evidence from German States, July 2007

2063 Ernesto Reuben and Arno Riedl, Public Goods Provision and Sanctioning in Privileged Groups, July 2007

2064 Jan Hanousek, Dana Hajkova and Randall K. Filer, A Rise by Any Other Name? Sensitivity of Growth Regressions to Data Source, July 2007

2065 Yin-Wong Cheung and Xing Wang Qian, Hoarding of International Reserves: Mrs Machlup’s Wardrobe and the Joneses, July 2007

2066 Sheilagh Ogilvie, 'Whatever Is, Is Right'?, Economic Institutions in Pre-Industrial Europe (Tawney Lecture 2006), August 2007

2067 Floriana Cerniglia and Laura Pagani, The European Union and the Member States: Which Level of Government Should Do what? An Empirical Analysis of Europeans' Preferences, August 2007

2068 Alessandro Balestrino and Cinzia Ciardi, Social Norms, Cognitive Dissonance and the Timing of Marriage, August 2007

2069 Massimo Bordignon, Exit and Voice. Yardstick versus Fiscal Competition across Governments, August 2007

2070 Emily Blanchard and Gerald Willmann, Political Stasis or Protectionist Rut? Policy Mechanisms for Trade Reform in a Democracy, August 2007

2071 Maarten Bosker and Harry Garretsen, Trade Costs, Market Access and Economic Geography: Why the Empirical Specification of Trade Costs Matters, August 2007 
2072 Marco Runkel and Guttorm Schjelderup, The Choice of Apportionment Factors under Formula Apportionment, August 2007

2073 Jay Pil Choi, Tying in Two-Sided Markets with Multi-Homing, August 2007

2074 Marcella Nicolini, Institutions and Offshoring Decision, August 2007

2075 Rainer Niemann, The Impact of Tax Uncertainty on Irreversible Investment, August 2007

2076 Nikitas Konstantinidis, Gradualism and Uncertainty in International Union Formation, August 2007

2077 Maria Bas and Ivan Ledezma, Market Access and the Evolution of within Plant Productivity in Chile, August 2007

2078 Friedrich Breyer and Stefan Hupfeld, On the Fairness of Early Retirement Provisions, August 2007

2079 Scott Alan Carson, Black and White Labor Market Outcomes in the $19^{\text {th }}$ Century American South, August 2007

2080 Christian Bauer, Paul De Grauwe and Stefan Reitz, Exchange Rates Dynamics in a Target Zone - A Heterogeneous Expectations Approach, August 2007

2081 Ana Rute Cardoso, Miguel Portela, Carla Sá and Fernando Alexandre, Demand for Higher Education Programs: The Impact of the Bologna Process, August 2007

2082 Christian Hopp and Axel Dreher, Do Differences in Institutional and Legal Environments Explain Cross-Country Variations in IPO Underpricing?, August 2007

2083 Hans-Werner Sinn, Pareto Optimality in the Extraction of Fossil Fuels and the Greenhouse Effect: A Note, August 2007

2084 Robert Fenge, Maximilian von Ehrlich and Matthias Wrede, Fiscal Competition, Convergence and Agglomeration, August 2007

2085 Volker Nitsch, Die Another Day: Duration in German Import Trade, August 2007

2086 Kam Ki Tang and Jie Zhang, Morbidity, Mortality, Health Expenditures and Annuitization, August 2007 